\title{
AVALIAÇÃO DA PRODUTIVIDADE E QUALIDADE DO CAPIM ELEFANTE E DO SORGO IRRIGADOS COM ÁGUA DO LENÇOL FREÁTICO E DO REJEITO DO DESSALINIZADOR
}

\author{
M. B. VALE ${ }^{1,2}$ e P. V. AZEVEDO ${ }^{2}$ \\ ${ }^{1}$ Instituto Federal do Rio Grande do Norte (IFRN) e ${ }^{2}$ Universidade Federal de Campina Grande (UFCG) \\ milton.vale@ifrn.edu.br e pvieira@dca.ufcg.edu.br
}

Artigo submetido em março/2013 e aceito em maio/2013

\begin{abstract}
RESUMO
O Experimento de campo foi conduzido (22/08/2012 a 02/01/2013) na comunidade "Riacho Salgado", município de São Paulo do Potengi-RN, objetivando avaliar a produtividade e a qualidade do capim elefante e do sorgo cujo solo foi irrigado com água do lençol freático e do rejeito do dessalinizador. Foram analisados os seguintes parâmetros de produtividade e qualidade nutricional: massa verde, massa seca e teor de proteína bruta das duas culturas. O aumento da salinidade da água de irrigação de $2,89 \mathrm{dS} / \mathrm{m}$ para $3,69 \mathrm{dS} / \mathrm{m}$ reduziu a altura das plantas, o teor de proteína bruta, a produtividade de massa verde e seca das duas culturas.
\end{abstract}

A produtividade do sorgo em relação a todos esses parâmetros foi superior àquela das duas cultivares do capim elefante, sendo a produtividade da cultivar do capim roxo relativamente superior àquela do capim verde. Dessa forma, o sorgo BRS Ponta Negra se apresenta como alternativa de sustentabilidade socioeconômica para o aproveitamento da água residual da dessalinização em sistema que apresente condições de salinidade igual ou inferior à estudada, garantindo, assim, uma fonte alternativa de renda e emprego para a agricultura familiar ou para Associação de Usuários de Água na região semiárida.

PALAVRAS-CHAVE: Rejeito de dessalinizador, Capim elefante, Sorgo BRS Ponta Negra, Produtividade.

\section{EVALUATION OF PRODUCTIVITY AND QUALITY OF ELEPHANT GRASS AND SORGHUM IRRIGATED WITH SOIL WATER TABLE AND REJECT OF THE DESALINATOR}

\begin{abstract}
A field experiment was conducted (08/22/2012 to 01/02/2013) on community "Riacho Salgado (Salt Creek)", São Paulo's Potengi-RN, to evaluate the productivity and quality of elephant grass and sorghum whose soil was irrigated with the ground water and desalination of waste. We analyzed the following parameters of productivity and nutritional quality: green mass, dry matter and crude protein content of the two cultures. The increased salinity of the irrigation water of $2.89 \mathrm{dS} / \mathrm{m}$ to $3.69 \mathrm{dS} / \mathrm{m}$ reduced plant height, the crude protein content, yield of green mass and dry of the two
\end{abstract}

cultures. The productivity of sorghum in relation to all these parameters was higher than that of two cultivars of elephant grass, and the productivity of the grass growing purple relatively higher than that of green grass. Thus, sorghum BRS Ponta Negra is an alternative socioeconomic sustainability to the use of waste water desalination system in which salinity conditions present at or below the study, thus ensuring an alternative source of income and employment for agriculture family or Water Users Association on semi-arid region.

KEYWORDS: Reject of desalination, Elephant grass, Sorghum BRS Ponta Negra, Productivity. 


\section{AVALIAÇÃO DA PRODUTIVIDADE E QUALIDADE DO CAPIM ELEFANTE E DO SORGO IRRIGADOS COM ÁGUA DO LENÇOL FREÁTICO E DO REJEITO DO DESSALINIZADOR}

\section{INTRODUÇÃO}

As regiões semiáridas se caracterizam climaticamente pelos baixos índices pluviométricos (350 a $700 \mathrm{~mm} / \mathrm{ano}$ ). Adicionalmente, apresentam elevados níveis de evapotranspiração (cerca de $2.000 \mathrm{~mm} / \mathrm{ano}$ ), de insolação ( 2.800 horas/ano) e temperaturas médias mensais superiores a $25^{\circ} \mathrm{C}$ (SANTOS et al. 2009). Apresentam, dessa forma, condições adversas para a agricultura de sequeiro e na criação de animais em determinada época do ano devido à falta de umidade no solo e na pastagem. Além dos recursos hídricos dessas regiões serem escassos, as águas subterrâneas apresentam elevados níveis de salinidade. Entretanto, essa fonte de água não doce, poderá se tornar necessária para a agricultura irrigada, devido à baixa disponibilidade de água doce e do aumento da demanda (RHOADES et al.,1992; SECKLER et al., 1998).

Em períodos de seca no semiárido nordestino, as águas do lençol freático, mesmo com elevados teores de sais, representam importante suporte de recurso hídrico para atender boa parte da necessidade da população, seja para o consumo humano através do uso da tecnologia de dessalinização da água, seja para dessedentação animal e para a agricultura familiar, através da irrigação de determinadas culturas agrícolas, principalmente aquelas mais adaptadas à salinidade como as halófitas (erva-sal) e outras menos tolerantes. Assim, enquanto o algodoeiro tolera alto nível de sal na água (até $6,4 \mathrm{dS} / \mathrm{m}$ ), o pimentão suporta apenas $1,5 \mathrm{dS} / \mathrm{m}$.

A água a ser usada na agricultura necessita tanto de quantidade quanto de qualidade. Em relação à qualidade, a água é analisada em função dos parâmetros físicos, químicos e biológicos, tais como: condutividade elétrica (salinidade), relação de adsorção de sódio (RAS) problemas de infiltração, concentração de íons (toxicidade) e pH (AYERS \& WESTCOT, 1991; EPA, 1991; ALMEIDA, 2010). Já Bernardo (1995) recomenda o aspecto sanitário da água com uso do parâmetro de coliformes termotolerantes. Os problemas relacionados à qualidade da água para irrigação podem interferir em cadeia no solo, na planta, no equipamento e na saúde do agricultor e do consumidor.

De acordo com Dias et al. (2011), a FAO recomenda a classificação da qualidade da água para irrigação proposta pela University of California Committee of Consultants (1974), divulgada por Ayers e Westcot (1991). No Brasil, o aspecto de sais na água foi estabelecido pela Comissão Nacional de Meio Ambiente - CONAMA, através da resolução 357/2005, com a classificação das águas como: doces, salobras e salinas.

A água salobra encontrada no subsolo do semiárido é transformada em doce e potável através de sistema de dessalinização, geralmente implantados por órgãos públicos, que utilizam a técnica da osmose reversa no tratamento da água. Essa tecnologia é utilizada no Rio 
Grande do Norte, como também em todo território Nacional. Esses dessalinizadores apresentam rejeito de água salgada igual ou superior a 50\%, o qual, na maioria dos casos, é lançado diretamente no meio ambiente sem nenhum tratamento. $O$ dispositivo mais utilizado para receber esses rejeitos é constituído por tanques, os quais apresentam rachaduras na sua maioria e alguns foram projetados de forma inadequada (FONSECA et al., 2005). Portanto, há a necessidade de aproveitamento desse rejeito, principalmente em projetos de irrigação, evitando a perda dessa água numa região tão carente de água, além de prevenir o impacto ambiental.

No estado do Rio Grande do Norte existem 379 dessalinizadores catalogados pela Secretaria de Estado de Meio Ambiente e dos Recursos Hídricos (SEMARH), os quais foram implantados pela própria SEMARH, como também pelo DNOCS, FUNASA, Fundação Banco do Brasil e prefeituras com recursos próprios ou financiados pelo PRONAF (Programa Nacional de Fortalecimento da Agricultura Familiar). Entretanto, apenas 142 equipamentos (37,5\%) estão em funcionamento e lançam seus efluentes com elevado teor de sais em tanques de evaporação com problemas de construção e de projeto ou então diretamente no solo (SILVA, 2010). A desvantagem da dessalinização da água com o uso da tecnologia da osmose reversa é o rejeito que possui alta concentração de sais que provocam impactos ambientais severos ao solo, haja vista que parte da região já sofre problema de salinização do solo (AMORIM et al., 2007). Segundo estudos de Ahmed et al. (2003), várias são as opções como destino do rejeito do dessalinizador, além da simples infiltração do solo: lagoas de evaporação; tanques de evaporação; processo de salmoura para extrair todos os sais; lançamento no mar; uso na aquicultura, através da criação de camarão, tilápia e artêmia salina; irrigação de culturas agrícolas tolerante e absorvedora de sais, tais como: atriplex e cevada.

No Nordeste do Brasil, a irrigação das plantas halófitas com efluente salino tem sido sugerida como uma alternativa para redução dos impactos ambientais dos sistemas de dessalinização. Estas plantas, além de suportar altos níveis de salinidade do complexo soloágua, sobrevivem em regiões de baixa precipitação e temperatura elevada. O arbusto Atriplex nummalaria (erva-sal) é uma das principais halófitas que funciona como um dessalinizador biológico do solo, acumulando grande quantidade de sais em seus tecidos (PORTO et al., 2001). Além da fitorremediação do solo, a erva-sal pode também, ser utilizada na alimentação animal (ovinos e caprinos) no semiárido do Nordeste do Brasil (ARAÚJO, 2006).

Atualmente, o semiárido nordestino dispõe de 14 Unidades Demonstrativas (UD) para aproveitamento do rejeito dos dessalinizadores. Essas Unidades Demonstrativas foram implantadas pelo Programa Água Doce (PAD), cujo rejeito possibilita a geração de recursos financeiros e alimentos para as famílias da comunidade, através da gestão dos recursos hídricos com a criação de peixe, principalmente a tilápia tailandesa, e cultivo de atriplex nummularia, além da gestão dos recursos hídricos com o fornecimento de água potável de boa qualidade para consumo (INGÁ, 2010). O Rio Grande do Norte possui apenas uma Unidade Demonstrativa implantada em 2006 pela Embrapa, a segunda do país que se localiza 
no assentamento de Caatinga Grande a $8 \mathrm{~km}$ de distância do centro da cidade de São José do Seridó/RN.

A falta da aceitação da atriplex como ração única para os animais, particularmente os bovinos e a escassez de alimento na época da seca na região do semiárido, leva à necessidade de pesquisar outras culturas que, consorciadas com a atriplex, possam elevar o grau de aceitabilidade pelos animais e de interesse pelos agricultores. Entre as culturas forrageiras se destacam como as de tolerância moderada ao estresse salino, aliada à alta produtividade e adaptação à região do semiárido, o sorgo (RHOADES et al., 1992) e o capim elefante (Dantas, 2004).

O sorgo apresenta moderada resistências à seca, possui característica bromatológica semelhante ao milho, favorecendo o processo da silagem (TABOSA et al., 2012) e, elevada produtividade de biomassa com menor custo de produção, permitindo mais de um corte com uma única semeadura. Isto resulta em economia no preparo do solo, na semeadura, no uso de sementes, maior densidade de plantas e com produção de até $60 \%$ do primeiro corte (VON PINHO et al., 2007). Entretanto, o aumento da condutividade elétrica do extrato de saturação do solo (CEes) reduz o rendimento em $50 \%$ a $15 \mathrm{dS} / \mathrm{m}$ e a $13 \mathrm{dS} / \mathrm{m}$ na emergência (RHOADES et al., 1992).

O capim elefante é, reconhecidamente, uma das gramíneas forrageiras mais utilizadas no Brasil e de alto potencial produtivo, adaptando-se bem como ração na alimentação animal, na forma de corte, de pastejo, na silagem e no feno. Segundo Alcântara e Bufarah (1983), o capim elefante vegeta bem em regiões quentes e úmidas com precipitação anual igual ou superior a $800 \mathrm{~mm}$, porém com boa distribuição ao longo do ano, por ser uma forrageira muito estacional, onde $70-80 \%$ de sua produção ocorre na época das águas. Possui baixa tolerância à seca, mas pode atravessar a estação seca com baixa produção se possuir raízes profundas. Difícil de saturar em relação à radiação solar e, por ser uma planta de metabolismo C4, possui alta eficiência fotossintética. Tem baixo custo de produção, pelo fato de ser planta perene e de alta produtividade.

Considerando o uso racional dos recursos hídricos, as ações permanentes de combate à seca e o uso da agricultura irrigada com culturas adaptadas a determinados níveis de sais, o presente estudo objetivou avaliar a produtividade e a qualidade do capim elefante e do sorgo irrigados com água do lençol freático e do rejeito do dessalinizador, na comunidade de "Riacho Salgado", município de São Paulo do Potengi/RN, localizado no semiárido potiguar.

\section{MATERIAL E MÉTODOS}

\section{DESCRIÇÃO E LOCALIZAÇÃO DA ÁREA EXPERIMENTAL}

Os experimentos de campo foram conduzidos na microrregião do Agreste Potiguar, na comunidade Riacho Salgado (6 $6^{\circ} 26^{\prime} 57^{\prime \prime}$ S; $\left.53^{\circ} 52^{\prime} 40^{\prime \prime} \mathrm{W}\right)$, distante $9 \mathrm{~km}$ da sede do município de São Paulo do Potengi - RN, durante a estação seca (outubro a dezembro) de 2012. A comunidade, localizada próximo ao riacho Salgado, apresenta relevo suave ondulado, altitude máxima de 112 m com cerca de 400 hectares de área, onde residem 20 famílias que vivem das 
atividades de agricultura e pecuária e fazem parte da Associação do Usuário de Água, criada em 2000 pela SEMARH com a implantação do dessalinizador.

A área experimental apresenta solo do tipo Planossolo Nátrico, com fertilidade natural alta, textura argilo-arenosa, imperfeitamente drenada e rasa. O clima da região é muito quente e semiárido, com precipitação anual média de 562,1 mm, umidade relativa do ar média anual de $70 \%$ e temperatura do ar média de $27,2{ }^{\circ} \mathrm{C}$.

Foram utilizadas duas áreas experimentais, distantes entre si em $80 \mathrm{~m}$, conforme a Figura 1. A área maior $(0,29$ ha), foi irrigada com o rejeito do dessalinizador, com condutividade elétrica igual a $3,7 \mathrm{dS} / \mathrm{m}$ e produção máxima diária de rejeito de $15 \mathrm{~m}^{3}$. A área menor (0,13 ha), foi irrigada com água proveniente do lençol freático (poço) que abastece o dessalinizador com condutividade elétrica de 2,9 dS/m. Cada área pesquisada foi dividida igualmente para as duas culturas, sorgo e capim elefante (dividida ao meio para o capim verde e capim roxo). O dessalinizador é constituído por um sistema de osmose reversa com uma membrana, 4 tanques de evaporação e um reservatório de $5 \mathrm{~m}^{3}$ para água potável.

O sistema produz 75\% de rejeito que foi enviado para reservatório de $5 \mathrm{~m}^{3}$ e, em seguida, para irrigação das duas culturas agrícolas. O dessalinizador é abastecido por água proveniente de poço tubular com vazão de $4.800 \mathrm{~L} / \mathrm{h}$.

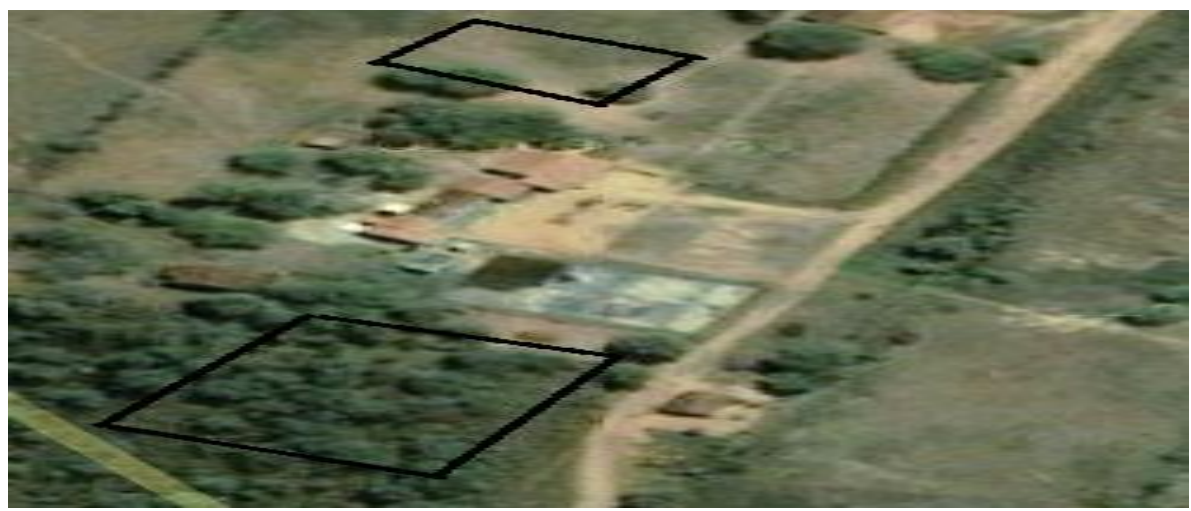

Figura 1 - Identificação das áreas experimentais utilizadas na pesquisa na comunidade "Riacho Salgado", município de São Paulo do Potengi/RN.

Fonte: Google Earth (2012)

\section{PREPARO DO SOLO}

Um trator com grade aradora de 16 discos fez o preparo do solo e em seguida, foi realizada a abertura de sulcos para aplicação da adubação química com fosfato monoamônico (MAP) 41,6 kg/ha para o sorgo e $21,3 \mathrm{~kg} / \mathrm{h}$ a para o capim, sulfato de amônio, $100,0 \mathrm{~kg} / \mathrm{ha}$ e 20 $\mathrm{kg} / \mathrm{ha}$ de FTE BR 12 para cada cultura, e adubação orgânica com esterco bovino, $15 \mathrm{~m}^{3} / \mathrm{ha}$ para o capim e $10 \mathrm{~m}^{3} /$ ha para o sorgo conforme recomendação da EMBRAPA e de acordo com a análise de fertilidade para macro e micronutrientes do solo da área experimental, para a camada de $0-30 \mathrm{~cm}$ de profundidade, com os seguintes resultados: 
a) solo da área menor: $\mathrm{pH}=7,21 ; \mathrm{Na}^{+}=24,00 \mathrm{cmol}_{\mathrm{c}} / \mathrm{dm}^{3} ; \mathrm{K}^{+}=317,00 \mathrm{cmol}_{\mathrm{c}} / \mathrm{dm}^{3} ; \mathrm{Al}^{3+}=$ $0,00 \mathrm{cmol}_{\mathrm{c}} / \mathrm{dm}^{3} ; \mathrm{Mg}^{2+}=1,95 \mathrm{cmol}_{\mathrm{c}} / \mathrm{dm}^{3} ; \mathrm{P}=81,00 \mathrm{mg} / \mathrm{dm}^{3} ; \mathrm{Fe}=38,60 \mathrm{mg} / \mathrm{dm}^{3} ; \mathrm{Cu}=1,05$ $\mathrm{mg} / \mathrm{dm}^{3} ; \mathrm{Zn}=5,67 \mathrm{mg} / \mathrm{dm}^{3} ; \mathrm{Mn}=23,82 \mathrm{mg} / \mathrm{dm}^{3}$ e $\mathrm{B}=7,14 \mathrm{mg} / \mathrm{dm}^{3}$.

b) solo da área maior: $\mathrm{pH}=6,76 ; \mathrm{Na}^{+}=143,00 \mathrm{cmol} / \mathrm{dm}^{3} ; \mathrm{K}^{+}=646,00 \mathrm{cmol}_{\mathrm{c}} / \mathrm{dm}^{3} ; \mathrm{Al}^{3+}$ $=0,0 \mathrm{cmol} / \mathrm{dm}^{3} ; \mathrm{Mg}^{2+}=3,20 \mathrm{cmol}_{\mathrm{c}} / \mathrm{dm}^{3} ; \mathrm{P}=82,00 \mathrm{mg} / \mathrm{dm}^{3} ; \mathrm{Fe}=60,27 \mathrm{mg} / \mathrm{dm}^{3} ; \mathrm{Cu}=0,75$ $\mathrm{mg} / \mathrm{dm}^{3} ; \mathrm{Zn}=6,41 \mathrm{mg} / \mathrm{dm}^{3} ; \mathrm{Mn}=38,91 \mathrm{mg} / \mathrm{dm}^{3}$ e $B=12,41 \mathrm{mg} / \mathrm{dm}^{3}$.

\section{IMPLANTAÇÃO DAS CULTURAS E TRATOS CULTURAIS}

Foram utilizadas as culturas do sorgo BRS Ponta Negra (Sorghum bicolor L. Moench) e do capim-elefante: roxo e verde (Pennisetum purpureum Schum.). A semente do sorgo foi semeada manualmente num espaçamento de $70 \mathrm{~cm}$ entre linhas por $20 \mathrm{~cm}$ entre plantas, com 4 sementes por cova a uma profundidade de 3 a $5 \mathrm{~cm}$. A germinação do sorgo ocorreu após 8 dias e o desbaste de plântulas foi realizada 15 dias após a germinação, tendo sido deixadas 10 plantas por metro linear e/ou duas plantas por cova quando possível. A semente de sorgo utilizada (BRS Ponta Negra) foi fornecida pela Empresa de Pesquisa Agropecuária do Rio Grande do Norte S/A (EMPARN) e foi desenvolvida em conjunto com a Empresa Brasileira de Pesquisa Agropecuária (EMBRAPA Milho e Sorgo) em 2005. A colheita foi efetuada manualmente aos 75 dias após a germinação.

O capim elefante foi plantado manualmente com estacas com três nós em fileiras simples, num espaçamento de 1,0 m entre linhas por 0,50 m entre plantas, com dois colmos por cova de 15 a $20 \mathrm{~cm}$ de profundidade, inclinados em forma de "V", ficando dois nós enterrados (Figura 2). A brotação das mudas ocorreu após 14 dias. As estacas de capim elefante verde e roxo foram obtidas na Barragem de Campo Grande em São Paulo do Potengi. A colheita foi realizada manualmente 60 e 75 dias após a germinação, respectivamente.

O controle das plantas daninhas foi realizado manualmente, até os 45 dias após o plantio, com capinas manuais. Em relação ao capim elefante não houve presença de pragas e doenças, porém no sorgo apareceu o pulgão, a lagarta do cartucho e a mosca branca, mas de forma não danosa ao cultivo que pudesse comprometer a produção, por essa razão, não foi aplicado qualquer agrotóxico, defensivo orgânico ou biológico.
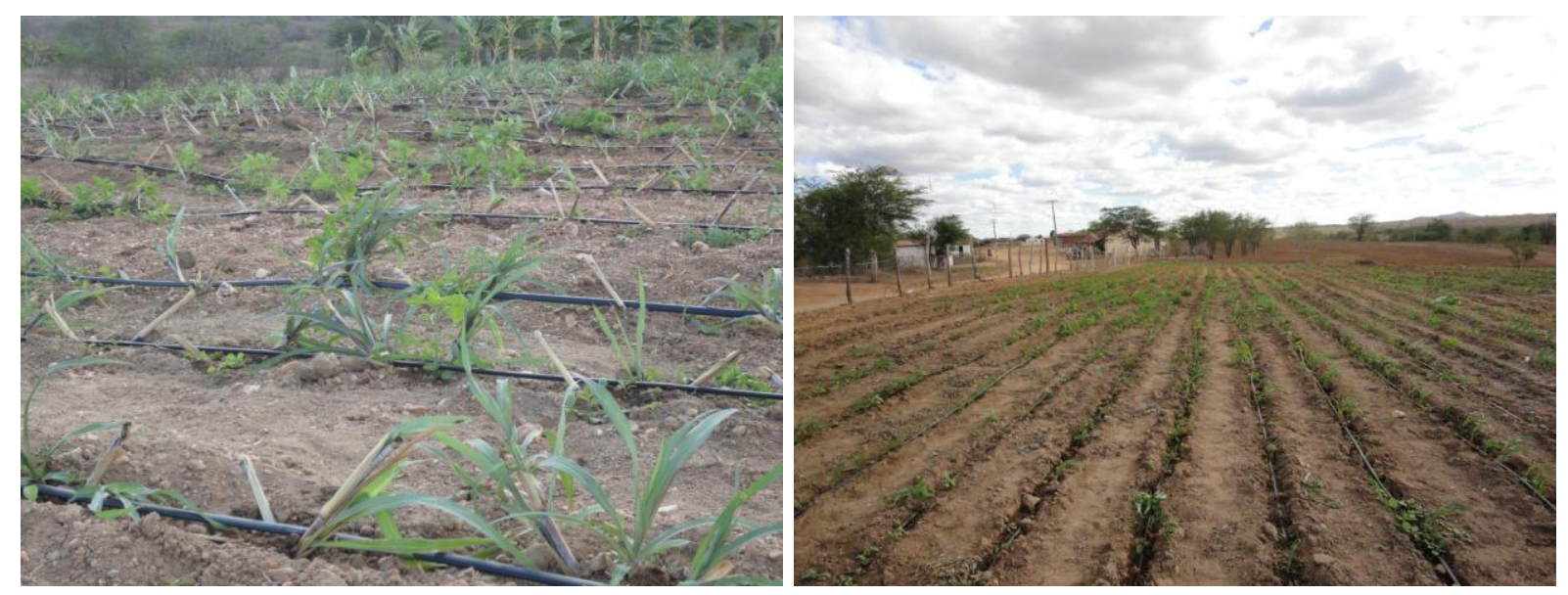

Figura 2 - Representação do sistema de semeadura e plantio do sorgo e do capim elefante nos experimentos de irrigação no tratamento 2 na comunidade "Riacho Salgado", município de São Paulo do Potengi/RN. 
A área menor (0,13 ha) foi irrigada com água do lençol freático, coletada diretamente do poço, enquanto que a área maior $(0,30 \mathrm{ha})$ foi irrigada com o rejeito do dessalinizador. As amostras de água foram analisadas no laboratório de Diretória de Recursos Naturais do IFRN de acordo com a metodologia de análise de água da APHA (2005), onde a classificação da água para irrigação teve com base em proposição do Comitê de Consultores da Universidade da Califórnia (1974) citado por Ayers e Westcot (1991).

Em ambas as áreas, a irrigação foi efetuada com gotejadores, com vazão de 7,5 L/s. Na adutora principal e secundária, foi utilizada uma tubulação de $35 \mathrm{~mm}$ e, nas linhas dos gotejadores, fitas de $12 \mathrm{~mm}$. Na área menor, a irrigação foi realizada diariamente, em dois turnos de rega, nas primeiras horas da manhã e ao fim da tarde, enquanto que, na área maior, a irrigado ocorreu em três turnos, manhã, tarde e noite.

\section{ALTURA DAS PLANTAS}

A altura média de plantas, correspondente à distância entre a superfície do solo e a curvatura das folhas superiores, foi realizada com amostragem de 20 plantas, aos 30, 45, 60 e 75 dias após a germinação e/ou brotação.

\section{PRODUTIVIDADE E QUALIDADE DAS FORRAGEIRAS}

Para a obtenção da produtividade e qualidade das forrageiras, foram utilizadas amostras de 20 plantas ( 5 por repetição), anteriormente selecionadas e representativas da população da parcela. O período final do ciclo vegetativo de cada cultura foi de 75 dias para o sorgo e de 60 e 75 dias para o capim elefante. A escolha da época dos cortes do capim elefante foi baseada no estudo de Dantas (2004) na qual a idade ideal de corte para obter bom valor nutritivo em relação à matéria seca é de 60 dias, então foi realizado dois cortes, o primeiro a 60 dias e o segundo de 75 dias para comparar com a produtividade do sorgo no mesmo período.

Inicialmente, mediu-se a altura média das plantas, as quais foram, em seguida, colhidas com o corte realizado rente ao solo e divididas em três frações: folhas, colmos + bainhas e panícula para a determinação da massa verde em balança eletrônica com precisão de 0,01 g. Para a determinação da massa seca, o material foi triturado e ensacado, para posteriores determinações no laboratório do IFRN, de acordo com a metodologia de SILVA (1999).

\section{PROTEINA BRUTA}

A determinação da proteína bruta foi realizada com amostragem de 20 plantas no período final do ciclo vegetativo de cada cultura de 75 dias para o sorgo e de 60 e 75 dias para o capim elefante. Para a determinação da proteína bruta, foram colhidas amostras, em torno de $500 \mathrm{~g}$, de cada fração da planta, inclusive a raiz, as quais foram trituradas, ensacadas e enviadas ao laboratório da EMPARN, para determinação desse parâmetro de acordo com a metodologia de SILVA (1999).

\section{RESULTADOS E DISCUSSÃO}




\section{CICLO FENOLÓGICO DAS CULTURAS}

A germinação do sorgo iniciou-se no quinto dia após a semeadura (DAS $=5$ ), tendo sido concluída no $8^{\circ}$ dia, com a formação de apenas $70 \%$ das plântulas nas duas áreas. $A$ formação das panículas teve início no 45으 dia após a germinação, e a maioria das plantas estava com as panículas abertas aos 75 dias após a germinação. O Capim elefante: roxo e verde apresentaram o mesmo ciclo, iniciando a brotação no $8^{\circ}$ dia e concluída no $15^{\circ}$ dia, com $87 \%$ de sobrevivência na área do menor e $80 \%$ na área maior, sendo que a cultivar roxo apresentou maior taxa de sobrevivência que o verde.

\section{ALTURA DAS PLANTAS}

Os valores médios de altura de plantas, obtidos a cada 15 dias, estão apresentados nas Tabelas 1 e 2. Aos 75 dias, o sorgo atingiu a altura média de $220,8 \mathrm{~cm}$ no tratamento T1 (irrigação com água do lençol freático) e $174,0 \mathrm{~cm}$ no tratamento T2 (irrigação com o rejeito do dessalinizador). Estudos realizados em Canguaretama/RN por Aguiar et al. (2008) com utilização de vários cultivares de sorgo forrageiro em regime de sequeiro, observaram uma altura média $320,0 \mathrm{~cm}$, enquanto que o sorgo BR Ponta Negra atingiu a altura média de 218,0 $\mathrm{cm}$. Santos et al. (2007), constatou, para quatro municípios do Rio Grande do Norte, uma altura de $220,0 \mathrm{~cm}$ para o sorgo forrageiro BRS Ponta Negra cultivado em condições de sequeiro. A altura média do sorgo do tratamento T1 ficou dentro da média enquanto que aquela do tratamento T2 ficou abaixo dos valores obtidos por Lima (2005) e das recomendações técnicas da distribuidora da semente de sorgo BRS Ponta Negra que estima a altura da planta de 220,0 a $250,0 \mathrm{~cm}$.

A altura das plantas do capim elefante: roxo e verde apresentou redução não significativa $(4,8 \%)$ no tratamento de irrigação $\mathrm{T} 1$, sendo praticamente igual (redução de $0,2 \%)$ no tratamento $T 2$. Foi observada uma redução na altura média do capim elefante de $22 \%$ do tratamento $\mathrm{T} 2$ em relação ao tratamento $\mathrm{T} 1$, enquanto que para o sorgo essa redução foi de $20 \%$ (Tabelas 1 e 2). A altura do capim elefante é uma importante indicador para se obter melhor condições de pastejo e qualidade nutricional. As alturas do capim elefante obtidas nesta pesquisa no tratamento I são semelhantes às relatadas por Magalhães (2006), em pesquisa realizada em Parnaíba-PI, com o capim elefante cv. Napier irrigado com água doce e por Saraiva e Konig (2013) com o capim elefante cv. Roxo irrigado com efluentes de esgoto tratado em Pendências/RN.

Tabela 1 - Altura média $(\mathrm{cm})$ das plantas de Capim elefante: roxo e verde e sorgo irrigados com água do lençol freático (poço), obtida a cada 15 dias após a emergência (DAE), com os respectivos desvios padrões (DP) e coeficientes de variação (CV \%).

\begin{tabular}{|c|c|c|c|c|c|c|c|c|c|}
\hline \multirow{3}{*}{$\begin{array}{c}\text { Data de coleta/ } \\
\text { Cultura }\end{array}$} & \multicolumn{9}{|c|}{ Altura das plantas $(\mathrm{cm})$} \\
\hline & \multicolumn{3}{|c|}{ Capim roxo } & \multicolumn{3}{|c|}{ Capim verde } & \multicolumn{3}{|c|}{ Sorgo } \\
\hline & Média & DP & CV \% & Média & DP & CV \% & Média & DP & CV \% \\
\hline $30 \mathrm{DAE}$ & 76,7 & 12,5 & 16,3 & 73,4 & 15,5 & 21,2 & 132,2 & 12,4 & 9,37 \\
\hline $45 \mathrm{DAE}$ & 99,8 & 30,4 & 30,5 & 105,0 & 20,8 & 19,8 & 172,8 & 37,0 & 21,4 \\
\hline
\end{tabular}




\begin{tabular}{cccccccccc}
\hline 60 DAE & 119,8 & 24,7 & 20,6 & 119,4 & 22,3 & 18,7 & 198,1 & 14,9 & 7,5 \\
\hline 75 DAE & 148,4 & 14,0 & 9,5 & 141,0 & 22,7 & 16,1 & 220,8 & 10,2 & 4,6
\end{tabular}

Tabela 2 - Altura média $(\mathrm{cm})$ das plantas de Capim elefante roxo e verde e sorgo irrigados com rejeito do dessalinizador, obtida a cada 15 dias após a emergência (DAE), com os respectivos desvios padrões (DP) e coeficientes de variação (CV \%).

\begin{tabular}{c|c|c|c|c|c|c|c|c|c}
\hline \multirow{2}{*}{$\begin{array}{c}\text { Data de coleta/ } \\
\text { Cultura }\end{array}$} & \multicolumn{8}{|c}{ Capim roxo } & \multicolumn{3}{c}{ Capim verde } & \multicolumn{3}{c}{ Sorgo } \\
\cline { 2 - 11 } & Média & DP & CV \% & Média & DP & CV \% & Média & DP & CV \% \\
\hline 30 DAE & 73,7 & 5,5 & 7,5 & 68,1 & 12,4 & 18,2 & 112,1 & 19,6 & 19,5 \\
\hline 45 DAE & 89,9 & 14,4 & 16,1 & 84,0 & 25,9 & 30,8 & 132,5 & 20,4 & 15,4 \\
\hline 60 DAE & 109.7 & 26,9 & 24,6 & 110,8 & 25,1 & 22,6 & 162,1 & 12,5 & 7,7 \\
\hline 75 DAE & 114,8 & 22,5 & 19,6 & 113,0 & 21,3 & 18,2 & 174,3 & 38,9 & 22,4 \\
\hline
\end{tabular}

\section{QUALIDADE DA ÁGUA}

A Tabela 3 sumariza as principais características da água de irrigação utilizada na pesquisa. $\mathrm{O} \mathrm{pH}$ é levemente elevado sobretudo na água de rejeito, porem próximo da neutralidade. A água do rejeito apresentou um aumento na salinidade em torno de $28 \%$ em relação à água do lençol freático, o que pode afetar ainda mais o desenvolvimento das culturas. Em relação à condutividade elétrica, as amostras de água foram classificadas, de acordo com tabela da UUUC - University of California Commitee of Consultantes (Ayers e Westcot, 1991), como de alto risco de salinidade $\left(1,5 \mathrm{dS} / \mathrm{m}<\mathrm{C}_{3}<3,0 \mathrm{dS} / \mathrm{m}\right.$ - água do lençol freático) mas com muito maior risco de salinidade $\left(C_{4}>3,0 \mathrm{dS} / \mathrm{m}\right.$ - água do rejeito). Assim, a água do tratamento de irrigação T1 (lençol freático) apresentou alto risco de salinidade enquanto que a do tratamento T2 (rejeito do dessalinizador) apresentou muito alto risco de salinidade. A razão de adsorção de sódio (RAS) é o indicador mais adequado e adotado para avaliar a sodicidade das águas e sua capacidade de sodificação do solo. A RAS ${ }^{\circ}$ corrigida apresenta classificação de risco mais adequada ao efeito do sódio. Para ambos os tratamentos de irrigação (lençol freático e rejeito do dessalinizador), a RAS apresentou baixo risco de sodicidade (S1) e severo risco de toxicidade em relação ao sódio $\left(T_{3}\right)$. Assim como, segundo Holanda et al. (2010), o sorgo tolera 10 a $20 \mathrm{mmol}_{\mathrm{c}} / \mathrm{L}$ de sódio e de cloreto em água, no experimento, encontrando-se dentro do limite estipulado. O risco sanitário (Coliformes termotolerantes $=4,0 \mathrm{NMP} / 100 \mathrm{~mL}$ ) praticamente não existe, pois se encontra muito abaixo 
do limite estabelecido pela legislação brasileira (BRASIL, 2005) cujo valor não deverá exceder 200 coliformes termotolerantes por $100 \mathrm{~mL}$.

Tabela 3 - Características químicas e microbiológicas das águas utilizadas na irrigação do sorgo e do capim elefante na comunidade de “Riacho Salgado", município de São Paulo do Potengi/RN.

\begin{tabular}{lcc}
\hline \multicolumn{1}{c}{ Parâmetro } & $\begin{array}{c}\text { Água do lençol freático } \\
\text { Valor médio }\end{array}$ & $\begin{array}{c}\text { Água do rejeito } \\
\text { Valor médio }\end{array}$ \\
\hline $\mathrm{pH}$ & 7,40 & 7,7 \\
\hline Condutividade elétrica, $\mathrm{dS} / \mathrm{m}$ & 2,89 & 3,69 \\
\hline Cálcio, $\mathrm{mmol} / \mathrm{L}$ & 4,26 & 5,82 \\
\hline Magnésio, $\mathrm{mmol} / \mathrm{L}$ & 8,61 & 11,97 \\
\hline Sódio, $\mathrm{mmol} / \mathrm{L}$ & 14,04 & 17,04 \\
\hline Potássio, $\mathrm{mmol} / \mathrm{L}$ & 0,44 & 0,58 \\
\hline Bicarbonato, $\mathrm{mmol} / \mathrm{L}$ & 18,31 & 8,70 \\
\hline Carbonato, $\mathrm{mmol} / \mathrm{L}$ & 0,00 & 0,00 \\
\hline Cloreto, $\mathrm{mmol} / \mathrm{L}$ & 18,31 & 26,90 \\
\hline $\begin{array}{l}\text { Coliformes termotolerantes } \\
\text { (NMP/100 mL) }\end{array}$ & 4,50 & 4,00 \\
\hline RAS ${ }^{\circ}(\mathrm{mmol} / \mathrm{L}$ ) & & 6,64 \\
\hline Classe de água para irrigação & 6,19 & $\mathrm{C}_{4} \mathrm{~S}_{1} \mathrm{~T}_{3}$ \\
\hline
\end{tabular}

\section{PRODUÇÃO DE MASSA VERDE E MASSA SECA}

Os valores médios da massa: verde e seca do capim elefante, obtidos no período entre 60 e 75 dias após a emergência e do sorgo aos 75 dias após a emergência, são apresentados na Tabela 4. Verificou-se que o aumento da salinidade diminuiu a massa verde e seca de todas as forrageiras estudadas.

A alta produção de massa verde do sorgo avaliado (Tabela 04) irrigado com água do poço tubular correspondente a um hectare foi estimada em $47,5 \mathrm{t} / \mathrm{ha}$, enquanto a massa verde irrigada com água do rejeito do dessalinizador ocorreu redução de $20,4 \%$. Entretanto, a produção de biomassa verde de ambos os tratamentos estudados, manteve-se próximo ou superior à média obtida por Cunha e Lima (2010), Aguiar et al. (2008), Santos, et al. (2007) e Paulo et al. (2008) cultivada em sequeiro que obtiveram por corte, 46,7 t/ha, 40,37 t/ha, $51,70 \mathrm{t} / \mathrm{ha}$ e $33,70 \mathrm{t} / \mathrm{ha}$, respectivamente. Porém, obtivemos valores inferiores a Vieira et al. (2005) que obteve 57,0 t/ha e 64,7 t/ha de sorgo forrageiro genótipo CSF 18 colhido com 112 dias com uso de água de condutividade elétrica de $0,90 \mathrm{dS} / \mathrm{m}$ e 5,80 dS/m, respectivamente. 
Também ficou aquém da produtividade obtida por Lima et al. (2012) que estudou o comportamento do sorgo forrageiro BRS Ponta Negra irrigado com água doce no Rio Grande do Norte e obtiveram por corte $82 \mathrm{t} /$ ha de massa verde.

Tabela 4. Valores de massa verde (MV) $t /$ ha, massa seca (MS) $t /$ ha e percentual de massa seca (\%MS) do capim elefante e do sorgo obtidos aos 60 e 75 dias após a emergência (DAE).

\begin{tabular}{|c|c|c|c|c|c|c|c|c|c|}
\hline \multirow{2}{*}{$\begin{array}{c}\text { Área irrigada } \\
\text { (época do corte)/Cultura }\end{array}$} & \multicolumn{2}{|c|}{ Capim roxo } & \multicolumn{2}{|c|}{ Capim verde } & \multicolumn{2}{|c|}{ Sorgo } & \multicolumn{3}{|c|}{$\% \mathrm{MS}$} \\
\hline & MV & MS & MV & MS & MV & MS & CER & CEV & $\mathbf{S}$ \\
\hline Lençol freático (DAE = 60) & 19,4 & 3,9 & 17,8 & 3,5 & ND & ND & 20,1 & 19,7 & ND \\
\hline Lençol freático (DAE = 75) & 22,1 & 4,6 & 19,1 & 3,9 & 47,5 & 14,5 & 20,8 & 20,4 & 30,5 \\
\hline Rejeito (DAE = 60) & 15,3 & 2,6 & 13,9 & 2,6 & ND & ND & 18,5 & 18,3 & ND \\
\hline Rejeito (DAE = 75) & 16,7 & 3,4 & 14,5 & 2,9 & 37,8 & 11,0 & 20,4 & 20,0 & 29,1 \\
\hline
\end{tabular}

A produção da massa verde do capim elefante foi maior na cultivar roxo em todos os tratamentos e idades de corte. Ocorreu redução na massa verde com o aumento da salinidade, relação capim elefante roxo e verde foram de $21,1 \%$ e 21,9 no corte realizado aos 60 dias e $24,4 \%$ e $24,1 \%$ no corte 75 dias, respectivamente, em relação aos dois tratamentos. Os valores obtidos foram inferiores aos encontrados na literatura com uso de água doce, tais como, DANTAS et al. (2002) obtiveram 35,8 t/ha/corte, com o cultivar Mott. Entretanto a massa verde do capim elefante irrigada com água do lençol freático ficou no limite mínimo recomendado por Lima (2007a) que estima a produção de 20 a 30 t/ha no mesmo período.

O sorgo apresentou produção de matéria seca bem superior ao capim elefante, o resultado obtido de 14,5 t/ha foi superior ao relatado por Aguiar et al. (2008) com corte de 86 dias tendo obtido $11,2 \mathrm{t} /$ ha com $27,5 \% \mathrm{MS}$, ficou dentro da faixa de produtividade de Lima et al. (2007b) na qual a massa seca aceita é de 12 a 15 t/ha no ciclo de 105 dias com aplicação da mesma cultivar e uso de água doce.

Programamos a melhor época para o corte do capim-elefante aos 60 dias após a emergência, quando a maioria dos cultivares de capim-elefante apresenta uma produção média de matéria seca em torno de 6,5 t/ha (Dantas, 2004). Entretanto, nosso experimento ficou abaixo para as duas cultivares e os dois tratamentos empregados. Também ficou abaixo da produção obtido por Machado et al. (1996) na qual o plantio foi realizado com o mesmo espaçamento com rendimento de 13,0 t/ha cujo corte ocorreu aos 113 dias após a emergência.

PROTEÍNA BRUTA 
Os valores acumulados da proteína bruta obtidos a 60 e 75 dias após a emergência, estão expostos na Tabela 5. O aumento da salinidade da água de irrigação provocou reduções nos teores de proteína bruta nas duas culturas estudadas. Verificou-se que nas gramíneas tropicais, o aumento na idade da planta é acompanhada da queda do valor nutritivo de acordo Acunha et al. (1997). O sorgo apresentou maior teor de proteína do que o capim elefante na mesma época de corte. Em relação ao capim elefante a cultivar roxo apresentou maior concentração de proteína. A maior quantidade de proteína bruta encontra-se nas folhas das duas culturas, entretanto sorgo BRS Ponta Negra o desempenho produtivo da panícula foi comprometido devido ao consumo de grãos pelos pássaros existentes na área de estudo. Os resultados de proteínas obtidos para o sorgo BRS Ponta Negra foram superiores aos observados por Vieira et al. (2005) e atende aos teores mínimos de proteínas nos alimentos dos animais ruminantes. No entanto, foi inferior obtidos por Santos et al. (2007) e Lima et al. (2007b) que foi igual $16,2 \%$ para a proteína existente nas folhas do sorgo da mesma cultivar.

Tabela 5. Valores de proteína bruta (\%) acumulados nas partes do capim elefante e do sorgo, folha ( $F)$, colmo (C), raiz (R) e Panícula (P) aos 60 e 75 dias após a germinação.

\begin{tabular}{|c|c|c|c|c|c|c|c|c|c|c|}
\hline \multirow{2}{*}{$\begin{array}{l}\text { Área irrigada e idade } \\
\text { do corte/cultura }\end{array}$} & \multicolumn{3}{|c|}{ Capim roxo } & \multicolumn{3}{|c|}{ Capim verde } & \multicolumn{4}{|c|}{ Sorgo } \\
\hline & $\mathrm{F}$ & C & $\mathrm{R}$ & $\mathrm{F}$ & $\mathrm{C}$ & $\mathrm{R}$ & $\mathrm{F}$ & C & $\mathrm{R}$ & $P$ \\
\hline $\mathrm{T} 1-60$ dias & 10,21 & 7,74 & 5,38 & 8,73 & 7,66 & 5,27 & ND & ND & ND & ND \\
\hline T1 - 75 dias & 7,49 & 5,51 & 5,10 & 7,08 & 6,01 & 3,95 & 12,02 & 2,72 & 3,42 & 8,64 \\
\hline $\mathrm{T} 2-60$ dias & 9,22 & 6,91 & 3,62 & 7,66 & 5,76 & 3,62 & ND & ND & ND & ND \\
\hline $\mathrm{T} 2-75$ dias & 5,87 & 3,68 & 3,54 & 4,67 & 3,18 & 3,26 & 7,14 & 2,49 & 3,26 & 5,31 \\
\hline
\end{tabular}

$\mathrm{ND}=$ não determinado, $\mathrm{T} 1$ = tratamento com água do lençol freático, $\mathrm{T} 2$ = tratamento com água do rejeito.

Em relação ao capim elefante os valores obtidos para a proteína bruta foram inferiores aos observados por Acunha et al. (1997) utilizando capim elefante anão cortado em 56 dias registro de $9,5 \%$ e $7,9 \%$ em 84 dias. No entanto, foram próximos da média de $8 \%$ encontrados na pesquisa realizado por Dantas (2004) de vários artigos cuja proteína bruta varia de 4,26 a $15,3 \%$, porém o capim elefante irrigado com rejeito do dessalinizador ficou abaixo.

\section{CONCLUSÕES}

Os resultados da análise da produtividade e qualidade do capim elefante e do sorgo irrigados com água do lençol freático e do rejeito do dessalinizador, na comunidade de "Riacho Salgado", município de São Paulo do Potengi/RN permitem concluir que:

1) Os efeitos da salinidade da água se refletiram sobre sorgo BRS Ponta Negra e o capim elefante roxo e verde, reduzindo a altura, o teor de proteína bruta e o acúmulo de biomassa verde e seca, de modo que a irrigação com rejeito da dessalinização da água apresentou valores inferiores em todos os parâmetros estudados em relação à água do lençol freático. 
2) O sorgo BRS Ponta Negra foi mais produtivo que o capim elefante em relação à biomassa verde e seca, e a proteína bruta para o mesmo período de corte, sendo a produtividade do capim elefante roxo relativamente superior àquela do capim elefante verde.

3) Os resultados obtidos, tanto em termos qualitativo como quantitativos, sugerem o uso potencial de sorgo forrageiro BRS Ponta Negra em relação ao capim elefante quando irrigado com águas com moderados níveis de salinidade. O sorgo Ponta Negra por possuir características apropriadas ao semiárido nordestino e apresentar tolerância moderada à salinidade, apresenta-se como alternativa para o aproveitamento do rejeito da dessalinização de água por osmose reversa desde que apresente condições de salinidade da água igual ou inferior à estudada, gerando uma fonte alternativa de renda aos associados de Usuários de Água, habitantes do semiárido nordestino.

\section{REFERÊNCIAS BIBLIOGRÁFICAS}

1. AGUIAR, E.M.; LIMA, J.M.P.; CUNHA, E.E.; FREITAS, M.O.; GOUVEIA, H. S. A.; MELO, A.B.; CASTRO, O.P. C.M. Caracterização de acessos, repetibilidade e herdabilidade de características produtivas de sorgo forrageiro cultivado no litoral potiguar. 45a Reunião Anual da Sociedade Brasileira de Zootecnia. Lavras, Mg, 2008.

2. ACUNHA, J.B.V; COELHO, R.W. Efeito da altura e intervalo de corte do capim-elefante anão: produção e qualidade da forragem. Pesquisa Agropecuária Brasileira, Brasília, v. 32, n. 1, p. 117-122, 1997.

3. AHMED, M.; ARAKEL, A.; HOEY, D.; THUMARUKUDY, M. R.; GOOSEN, M. F. A.; HADDABI, M. A.; BELUSHI, A. A. Feasibility of salt production from inland $R O$ desalination plant reject brine: a case study. Desalination, Amsterdam, v.158, n.1-3, p.109-117, 2003.

4. ALMEIDA, O.A. Qualidade da água para irrigação. Embrapa Mandioca e Fruticultura, 2010.

5. ALCÂNTARA, P.B., BUFARAH, G. Plantas forrageiras: gramíneas e leguminosas. São Paulo, Editora Nobel, 2a ed., 1983, 150p.

6. AMERICAN PUBLIC HEALTH ASSOCIATION (APHA) et al. Standard Methods for the Examination of Water and Wastewater. 20th edition. Public Health Association Inc., New York, 2005.

7. AMORIM, M. C. C.; SILVA JÚNIOR, L. G. A.; PORTO, E. R. Efeito de sais no solo provenientes de rejeitos da dessalinização por osmose inversa no semi-árido Pernambucano. In: Congresso Brasileiro de Engenharia Agrícola; 26, 1997, Campina Grande. Anais... Campina Grande: SBEA, 1997. CD Rom

8. ARAÚJO, G. G. L. de. Produção e uso do feno da erva sal na alimentação de caprinos e ovinos no semiárido. Petrolina, PE. Embrapa Semiárido, 2006. 33 p. (MMA/SRH, Embrapa Semiárido. Cartilha do PAD).

9. AYERS, R.S.; WESTCOT, D.W. A qualidade da água na agricultura. Traduzido por H.R. Gheyl, J.F. de Medeiros, F.A.V. Damasceno. Campina Grande: UFPB, 1991, 218p. (FAO. Estudos de Irrigação e Drenagem, 29, rev. 1).

10. BERNARDO, S. Manual de Irrigação. Viçosa: Imprensa Universitária, 1995. 657 p.

11. BRASIL. Ministério do Meio Ambiente. CONAMA - Conselho Nacional do Meio Ambiente. Resolução no 357, de 17 de março de 2005. 
12. CUNHA, E.E. LIMA, J.M.P. Caracterização de genótipos e estimativa de parâmetros genéticos de características produtivas de sorgo forrageiro, Revista Brasileira de Zootecnia, v.39, n.4, p.701-706, 2010.

13. DANTAS, J.A.; BEZERRA NETO, E.; AGUIAR, E.M. Efeito da adubação nitrogenada no desenvolvimento vegetativo do capim-elefante cv. "mott" em dois tipos de solos. In: Reunião Anual da Sociedade Brasileira de Zootecnia, 39a. Recife, 2002; UFRPE. Anais. Forragicultura.

14. DANTAS, J.A. Seleção e Avaliação de Clones de Pennisetum Sob Estresse Salino. Tese em Zootecnia na Universidade Federal Rural de Pernambuco. 2004

15. DIAS, N.S.; SILVA, M.R.F.; GHEYI, H,R. (ORG). Recursos hídricos usos e manejos. São Paulo, Editora Livraria da Física, 2011, 152p.

16. EPA Environmental Protection Agency. In: National Primary Drinking Water Regulations Current Driking Water Standards. Office of Water. 1991.

17. FONSECA, A. L.; VALE, M. B.; ARAÚJO, A. L. C.; FERNANDES, A. K. S.; GADELHA, C. P. F. Avaliação dos sistemas de dessalinização de águas no semiárido no Rio Grande do Norte. 23을 Congresso Brasileiro de Engenharia Sanitária e Ambiental, Campo Grande/MS, 2005.

18. HOLANDA, J. S.; AMORIM, J. R. A.; FERREIRA NETO, M.; HOLANDA, A. C. Qualidade da água para irrigação. In: GHEYI, H. R.; DIAS, N. S.; LACERDA, C. F. Manejo da salinidade na agricultura: Estudos básicos e aplicados. Fortaleza: Instituto Nacional de Ciência e Tecnologia em Salinidade, 2010. p. 43-61.

19. INGÁ - Instituto de Gestão das Águas e Clima. Plano Estadual do Programa Água Doce: Estado da Bahia (2010-2019). Salvador, 2010, 158p.

20. LIMA, G.F. C; ARAÚJO, G.G.L; MACIEL, F.C. Produção e conservação de forragens em escala para sustentabilidade dos rebanhos caprinos e ovinos na agricultura de base familiar. In: Simpósio Internacional Sobre Caprinos e Ovinos de Corte, 3., 2007, João Pessoa. Anais... João Pessoa: SEBRAE-PB: EMEPA-PB, 2007a. 1 CD-ROM.

21. LIMA, J.M.P. BRS Ponta Negra - Sorgo com grande potencial forrageiro. Emparn/Embrapa. Folder. Natal, RN, 2005.

22. LIMA, J. M. P.; LIMA, M. L.; LIRA, M. A.; DANTAS, J. A. Nova Cultivar de sorgo forrageiro de dupla finalidade para o SemiÁrido Nordestino. Parnamirim: EMPARN: 2007b. Disponível em:

<http://www.emater.rn.gov.br/contentproducao/aplicacao/emparn/arquivos/publicacoes /Jo\%E3o\%20. Acesso em: 13 nov, 2012.

23. LIMA, J.M.P.; LIMA, M.L.; DANTAS, J.A.; FREITAS, M.O.; OLIVEIRA, J.S.F. Comportamento de cultivares de sorgo forrageiro irrigado no Rio Grande do Norte. Disponível em: <http://www.emparn.rn.gov.br/links/publicaçoes>. Acesso em 11 de dezembro de 2012.

24. MACHADO, A.N., SIEWERDT, L., SILVEIRA JÚNIOR, P., SIEWERDT, F. Efeito do espaçamento de plantio na produção e qualidade de forragem capim elefante cv. Três Rios. Rev. Bras. de Agrociência, v.2, n.1, p.57-62, 1996.

25. MAGALHÃES, J. A.; LOPES, E. A.; RODRIGUES, B. H. N.; COSTA, N. L.; BARROS, N. N.; MATTEI, D. A. Influência da adubação nitrogenada e da idade de corte sobre o rendimento forrageiro do capim-elefante, Revista Ciência Agronômica, v.37, p.91-96, 2006.

26. PAULO, J. L. A.; FREITAS, M. O. Desempenho produtivo do sorgo forrageiro (sorghum bicolor (I.) moench) variedade BRS Ponta Negra no litoral do RN. In: ZOOTEC 2008, João Pessoa. Anais.. João Pessoa: Associação Brasileira de Zootecnistas, 2008. 3p. 
27. PORTO, E. R.; AMORIM, M. C. C.; SILVA JÚNIOR, L. G. A. Uso do rejeito da dessalinização de água salobra para irrigação da erva-sal (Atriplex nummularia). Revista Brasileira de Engenharia Agrícola e Ambiental, Campina Grande, v. 5, n. 1, p. 111-114, 2001.

28. RHOADES, J.D.; KANDIAH, A.; MASHALI, A.M. The use of saline waters for crop production. Rome: FAO, 1992. 133p. (FAO. Irrigation and Drainage Paper, 48).

29. SANTOS, O. O.; ARAÚJO, G. G. L. de; MISTURA, C.; PEREIRA, L. G. R.; PORTO, E. R.; ARAÚJO, J. R. de; BRANDÃO, L. G. N. Ácidos orgânicos em silagens de erva-sal com diferentes proporções de capim-elefante. In: REUNIÃO ANUAL DA SOCIEDADE BRASILEIRA DE ZOOTECNIA, 46., 2009, Maringá. Inovação científica e tecnológica em zootecnia: anais dos resumos. Maringá: SBZ: UEM, 2009b. 1 CD-ROM.

30. SANTOS F. G.; RODRIGUES, J. A. S.; SCHAFFERT, R. E.; LIMA, J. M. P.; PITTA, G. V. E.; CASELA, C. R.; SILVA, FERREIRA, A. S. BRS Ponta Negra Variedade de Sorgo Forrageiro. Sete Lagoas: Embrapa Milho e Sorgo, 2007. (Comunicado Técnico, 145).

31. SARAIVA, V. M. e Konig, A. Produtividade do capim-elefante-roxo irrigado com efluente doméstico tratado no semiárido potiguar e suas utilidades. Revista Holos. Vol 1, p28-46, 2013.

32. SECKLER, D.; AMARASINGHE, U.; MOLDEM, D.; SILVA, R. \& BAKER, R. World water demand and supply, 1990 to 2025: Scenarios and Issues. Colombo, International Water Management Institute, 1998. 41p. (Research Report, 19).

33. SILVA, F.C. Manual de análises químicas de solos, plantas e fertilizantes. Brasília: Embrapa Comunicação para Transferência de Tecnologia, 1999. 370p.

34. SILVA, E. V. Diagnóstico da situação dos dessalinizadores do Estado do Rio Grande do Norte. Monografia em Tecnologia em Gestão Ambiental, IFRN, Natal, 2010, 47p.

35. TABOSA, J.N.; SILVA, F.G.; NASCIMENTO, M.M.A.; BARROS, A.H.C.; BRITO, A.R.M.B.; SIMPLÍCIO, J.B.. Genótipos de Sorgo Forrageiro no Semiárido de Pernambuco e Alagoas Estimativas de Parâmetros Genéticos de variáveis de Produção. XXIX CONGRESSO NACIONAL DE MILHO E SORGO - Águas de Lindóia, São Paulo, 2012.

36. VIEIRA, M.R; LACERDA, C.F; CÂNDIDO M.J.D; CARVALHO, P.L; COSTA R.N.T;TABOSA, J.N. Produtividade e qualidade da forragem de sorgo irrigado com águas salinas. Rev. Bras. Eng. Agric. Amb. 9:42-46,2005.

37. VON PINHO, R. G.; VASCONCELOS, R. C.; BORGES, I. D.; RESENDE, A. V. Produtividade e qualidade da silagem de milho e sorgo em função da época de semeadura. Bragantia. v.66, n.2, p.235-245, 2007. 